Research Article

\title{
Analytical Assessment of Internal Stress in Cemented Paste Backfill
}

\author{
Naifei Liu $\mathbb{D}^{1,2}$ Liang Cui ${ }^{1},{ }^{3}$ and Yan Wang ${ }^{3}$ \\ ${ }^{1}$ School of Civil Engineering, Xi'an University of Architecture and Technology, Xi'an 710055, China \\ ${ }^{2}$ Shaanxi Key Laboratory of Geotechnical and Underground Space Engineering,XAUAT, Xi'an 710055, China \\ ${ }^{3}$ Department of Civil Engineering, Lakehead University, Thunder Bay, Ontario P7B 5E1, Canada \\ Correspondence should be addressed to Naifei Liu; liunaifei@xauat.edu.cn and Liang Cui; liang.cui@lakeheadu.ca
}

Received 27 October 2020; Revised 4 December 2020; Accepted 4 December 2020; Published 22 December 2020

Academic Editor: Erol Yilmaz

Copyright (C) 2020 Naifei Liu et al. This is an open access article distributed under the Creative Commons Attribution License, which permits unrestricted use, distribution, and reproduction in any medium, provided the original work is properly cited.

To analytically describe the internal stress in a fill mass made of granular man-made material (cemented paste backfill, CPB), a new 3D effective stress model is developed. The developed model integrates Bishop effective stress principle, water retention relationship, and arching effect. All model parameters are determined from measurable experimental data. The uncertainties of the model parameters are examined by sensitivity analysis. A series of model application is conducted to investigate the effects of field conditions on the internal stress in CPB. The obtained results show that the proposed model is able to capture the influence of operation time, stope geometry, and rock/CPB interface properties on the effective stress in CPB. Hence, the developed model can be used as a useful tool for the optimal design of $\mathrm{CPB}$ structure.

\section{Introduction}

As a relatively new backfilling method, cemented paste backfill (CPB, a mixture of dewatered tailings, hydraulic binder, and water) technology has gradually become a standard practice around the world $[1,2]$. Due to the rapid strength acquisition [3], СPB can provide reliable ground support to the adjacent stopes and thus enhance mining cycles and productivity. In addition, since the tailings are used as the major ingredient for the $\mathrm{CPB}$ preparation and then pumped into mined-out underground space (called stope), CPB technology can be considered as an effective and attractive alternative to the conventional tailings disposal on the surface (i.e., tailings impoundments or dams) [4] and thus enhances the associated mechanical (strength and stability) [5] and microstructural (total porosity and pore size distribution) properties [6] and minimizes the associated environmental issues (e.g., the acid mine drainage, acid/sulphate attack, heavy metal concentration, and so on) [7-9]. Consequently, the CPB technology has been widely adopted in underground mining and started to replace the conventional backfilling methods (i.e., hydraulic fill and cemented rockfill) $[10,11]$.
However, the binder costs may reach up to $80 \%$ of the total backfill operating costs $[12,13]$. Therefore, optimal design of CPB becomes one of the major tasks for backfill engineers and researchers. The prerequisite for the optimal $\mathrm{CPB}$ design is to reliably assess the internal stress in CPB. Previous laboratory and field studies [14] have found that the rock/CPB interface resistance (i.e., the interface friction stress and adhesion) can dramatically reduce vertical stress acting on the stope floor (i.e., the arching effect). Moreover, the water drainage through the barricade (i.e., a retaining structure for fresh $\mathrm{CPB}$ constructed near the stope entrance) can cause the dissipation of pore-water pressure (PWP) [15] and thus affect the effective stress in $\mathrm{CPB}$ mass. Therefore, to accurately and reliably assess and predict the internal stress in $\mathrm{CPB}$, the hydraulic and mechanical processes under the influence of rock/CPB interface interaction must be fully considered.

To study the variation of internal stress and the associated influencing factors, extensive laboratory experiments and in-situ monitoring programs have been conducted. For example, previous laboratory studies [16-20] have found that curing stress, water drainage, and structural filling 
properties (e.g., filling rate and sequences, filling time, filling interval time, and filling surface angle) affect the evolution of material properties (e.g., coefficient of permeability, shear strength parameters, elastic modulus, and so on) and the internal stress in CPB. Moreover, field monitoring programs have been carried out to assess the evolution of PWP [21] and total stress [22] in stopes with various mixture recipes and field conditions. The field measurements provide direct evidence for the arching effect in stopes. In addition, since the analytical models can provide a simple closed-form solution to assess the total stress in $\mathrm{CPB}$, the analytical method has been extensively used in the optimal design of $\mathrm{CPB}$ structure. Correspondingly, a series of analytical methods has been proposed through limit equilibrium analysis $[23,24]$. However, the skeletal deformation and its strength development are controlled by the effective stress rather than the total stress [25]. Therefore, it is necessary to investigate the changes of effective stress in CPB structure. However, the available analytical methods focus on the evaluation of total stress rather than the effective stress in CPB. Therefore, This study aims to (1) develop a 3D effective stress analytical model to evaluate the internal stress in CPB, which fully considers the effects of hydraulic and mechanical processes in $\mathrm{CPB}$ under the influence of rock/CPB interaction and (2) investigate the changes of internal stress of $\mathrm{CPB}$ mass with various filling operation time, stope geometry, and rock/CPB interface properties.

\section{Formulation of a 3D Effective Stress Analytical Model}

To develop a 3D effective stress analytical model for the characterization of internal stress in $\mathrm{CPB}$, the prerequisite is to determine the mechanisms responsible for the stress change. Then, the adopted assumptions for the derivation of the effective stress model should be identified. Afterwards, the limit equilibrium analysis can be carried out to derive the mathematical model. A schematic diagram (see Figure 1) of in-situ $\mathrm{CPB}$ mass in underground stope is adopted to elucidate the mechanisms of stress changes in $\mathrm{CPB}$.

As shown in Figure 1, the self-weight load increases with the backfilling operation after placement into stope. Meanwhile, the PWP progressively builds up with the filling process. However, the dissipation of PWP induced by barricade drainage accompanies the filling process. Correspondingly, negative PWP appears in the top area of $\mathrm{CPB}$ mass and changes the magnitude and spatial distribution of effective stress in CPB. In addition, the rock/CPB interface interaction can weaken the influence of selfweight stress on the vertical stress in fill mass [26]. Consequently, the resultant vertical stress can be apparently lower than the self-weight stress for a given elevation in $\mathrm{CPB}$. As aforementioned, the backfilling operation, rock/ $\mathrm{CPB}$ interface interaction, and barricade drainage control the changes of effective stress in fill mass. Considering the realistic underground mining conditions where variable rocks may exist as neighbour rock, the hard rock (igneous or metamorphic rock) is considered in this study.

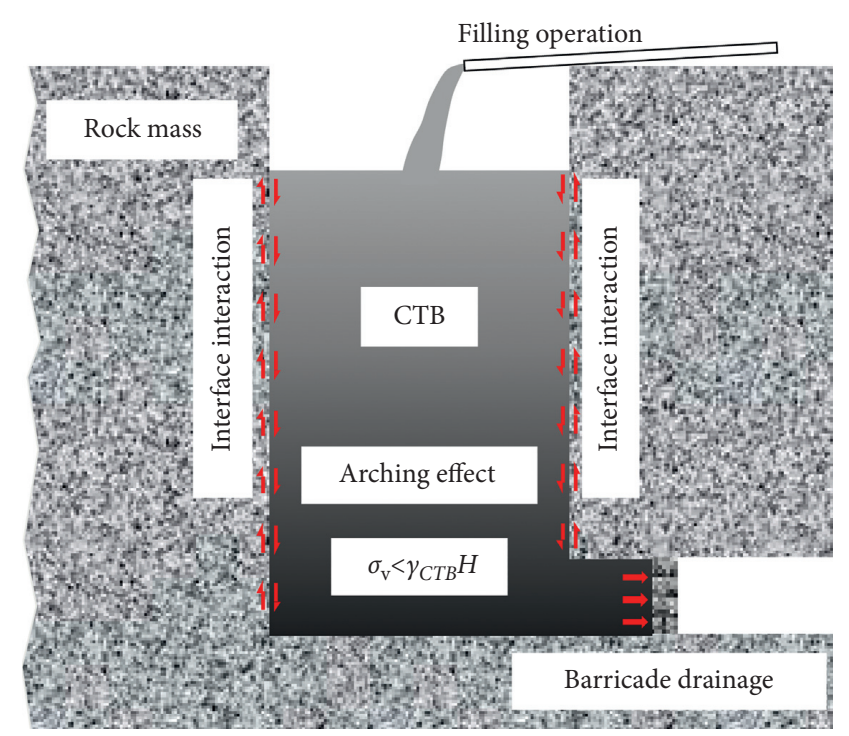

FIgURE 1: Schematic diagram of factors affecting the internal stress in stope $\left(\sigma_{v}\right.$ : total vertical stress, $\gamma_{\mathrm{CPB}}$ : unit weight of $\mathrm{CPB}$, and $H$ : filling height).

2.1. Definition of Effective Stress in CPB. Due to the barricade drainage, $\mathrm{PWP}$ dissipation takes place in $\mathrm{CPB}$ and thus causes the change of the saturation state. As a result, an unsaturated zone gradually appears in the top regime of fill mass and is separated from the saturated zone by the local water table. The variation of PWP affects the magnitude and spatial distribution of effective stress in CPB. To analytically describe the change of effective stress, Bishop effective stress $\sigma^{\prime}$ [27] is adopted:

$$
\sigma^{\prime}=\left(\sigma-P_{a}\right)+\chi\left(P_{a}-P_{w}\right)
$$

where $\sigma, P_{w}$, and $P_{a}$, respectively, represent total stress, PWP, and pore air pressure and $\chi$ is the parameter of Bishop effective stress $(\chi=1$ for saturated $\mathrm{CPB}$ and $\chi=0$ for dry $\mathrm{CPB})$. It has been found that Bishop's parameter $\chi$ is strongly dependent on the degree of saturation $S$ (i.e., $\chi=\chi(S)$ ) [28]. The latter can be determined by matric suction $\left(P_{w}-P_{a}\right)$ via the water retention curve. Therefore, Bishop's parameter $\chi$ can be related to matric suction as well. In this study, the empirical model proposed by Khalili and Khabbaz [29] is adopted to characterize the relationship between $\chi$ and matric suction $\left(P_{w}-P_{a}\right)$ :

$$
\chi=\left[\frac{\left(P_{a}-P_{w}\right)}{P_{e}}\right]^{R}
$$

where $P_{e}$ represents the air entry value and $R$ is a fitting parameter. Based on the experimental studies on 14 soils including glacial till, silts, sandy clay, and clays, $R=-0.55$ is obtained [29]. In terms of particle size, the tailings can range from fine sand down to clay-sized particles, which is very close to the investigated soils in the study conducted by Khalili and Khabbaz [29]. Therefore, $R=-0.55$ is adopted in the present study. Moreover, based on the previous study on the water retention curves (WRCs) of CPB [30], the air entry value $P_{e}=-200 \mathrm{kPa}$ is used in this study. In addition, it should be noted that equation (2) is only valid when the matric suction is greater than the air entry value; otherwise, 
the value of $\chi$ is equal to 1 [31], namely, the CPB remains fully saturated.

The pore air pressure is assumed to be zero-gauge pressure against atmospheric pressure (i.e., $P_{a}=0$ ). Therefore, by substituting equation (2) and $P_{a}=0$ into equation (1), the effective stress can be rewritten as follows:

$$
\sigma^{\prime}=\sigma+\frac{\left(-P_{w}\right)^{R+1}}{P_{e}^{R}} .
$$

To incorporate the effect of hydraulic process into the effective stress, the PWP in CPB (including both saturated and unsaturated zones) should be determined. For this purpose, the location (i.e., $H_{\mathrm{wt}}$ ) of local water table should be identified first. Then, the positive PWP in the saturated zone can be considered as hydrostatic pressure, and the negative PWP above the local water table can be determined by the spatial distribution of saturation degree and water retention relationship (i.e., the WRC model).

It should be noted that the location of local water table changes with time $t$ due to the water drainage through barricade. Hence, the thickness of the unsaturated zone $H_{\mathrm{wt}}$ can be expressed as follows:

$$
H_{\mathrm{wt}}=\int_{0}^{t} v_{\mathrm{wt}} \mathrm{d} t
$$

where $v_{\mathrm{wt}}$ is the movement velocity of local water table, which is related to the outflow rate $\bar{v}_{w b}$ of pore water through barricade. In this study, a linear relationship between $v_{\mathrm{wt}}$ and $\bar{v}_{\text {wb }}$ is assumed as follows:

$$
v_{\mathrm{wt}}=v_{f} \frac{l_{a} l_{b}}{L_{A} L_{B}} \bar{v}_{\mathrm{wb}},
$$

where $L_{A}$ and $L_{B}$, respectively, represent the length and width of the stope, la and $\mathrm{lb}$ refer to the barricade dimensions, and $v_{f}$ is a constant scaling parameter which is related to ratio of coefficient of permeability of CPB and barricade ( $v_{f}=K_{\mathrm{CPB} 0} / K_{B}$ with $K_{\mathrm{CPB} 0}$ and $K_{B}$ as the initial coefficient of permeability of $\mathrm{CPB}$ and barricade, respectively). The detailed information about the determination of $K_{\mathrm{CPB} 0}$ and $K_{B}$ will be presented in the Section of Determination of Model Parameters. The average pore-water flow velocity $\bar{v}_{\mathrm{wb}}$ through barricade can be calculated by Darcy's law:

$$
\bar{v}_{\mathrm{wb}}=K_{b} \frac{H-H_{\mathrm{wt}}}{W_{b}},
$$

where $K_{b}$ denotes the coefficient of permeability of barricade, $W_{b}$ is the thickness of barricade, and $H$ refers to the backfilling height and can be determined by filling rate $v_{\text {filling }}$ and filling strategy:

$$
H= \begin{cases}v_{\text {filling }} t, & H \leq H_{r 1}, \\ H_{r 1}+v_{\text {filling }}\left(t-t_{r 1}\right), & H_{r_{1}}<H \leq H_{r_{2}}, \\ \vdots & \\ \sum_{i=1}^{n-1} H_{r_{i}}+v_{\text {filling }}\left(t-t_{r_{n-1}}\right), & H_{r_{n-1}}<H \leq H_{r_{n}},\end{cases}
$$

where $H_{r i}$ is the total filling height after $i$-th filling sequence, $t_{r i}$ is the rest time between $i$-th filling and $(i+1)$-th filling sequences, and $n$ is the total filling sequences adopted by the backfilling operation. As indicated in equation (7), the filling rate and filling sequences are fully considered in the present study. Substituting equations (5) and (6) into equation (4) and applying the initial condition $\left(H_{\mathrm{wt}}=0\right.$ when $\left.t=0\right)$ yield the following:

$$
H_{w t}=H\left[1-\exp \left(-\frac{v_{f} K_{b}}{W_{b}} \frac{l_{a} l_{b}}{L_{A} L_{B}} t\right)\right] .
$$

Then, the effective saturation degree $S_{e}\left(S_{e}=\left(\theta-\theta_{\mathrm{r}}\right) /\right.$ $\left(\theta_{s}-\theta_{r}\right)$ with $\theta_{s}$ as saturated water content, $\theta$ as current water content, and $\theta_{r}$ as residual water content) is assumed to be linearly distributed in the unsaturated zone (i.e., $S_{e}=h / H_{\mathrm{wt}}$ with $h$ as the thickness of CPB relative to the top surface). Hence, the negative PWP in the unsaturated zone can be determined by the water retention curve (WRC). Previous studies [30,32] on CPB have proved that the van Genuchten model [33] is able to accurately predict the water retention capacity of CPB materials.

$$
S_{e}=\frac{1}{\left[1+\left(-\alpha P_{w}\right)^{1 / 1-m}\right]^{m}}
$$

where $\alpha$ and $m$ denote the parameters of the van Genuchten model. The detailed information about the determination of parameters of the WRC model will be provided in the Section of Determination of Model Parameters.

Therefore, the negative PWP can be derived by substituting the effective saturation degree (i.e., $S_{e}=h / H_{\mathrm{wt}}$ ) into the WRC model (i.e., equation (9)):

$$
P_{w}=-\frac{1}{\alpha}\left[\left(\frac{H_{m}}{h}\right)^{1 / m}-1\right]^{1-m} .
$$

Hence, the spatial distribution of effective stress in $\mathrm{CPB}$ mass can be expressed as follows:

$$
\begin{cases}\sigma^{\prime}=\sigma+\frac{\left\{(1 / \alpha)\left[\left(H_{\mathrm{wt}} / h\right)^{(1 / m)}-1\right]^{1-m}\right\}^{R+1}}{P_{e}^{R},} & h \leq H_{\mathrm{wt}}, \\ \sigma^{\prime}=\sigma-\gamma_{w}\left(h-H_{w t}\right), & h>H_{\mathrm{wt}},\end{cases}
$$

with

$$
H_{\mathrm{wt}}=H\left[1-\exp \left(-\frac{v_{f} K_{b}}{W_{b}} \frac{l_{a} l_{b}}{L_{A} L_{B}} t\right)\right],
$$

where $\gamma_{w}$ refers to the unit weight of pore water.

As previously discussed, the arching effect causes the discrepancy between vertical stress and the self-weight stress. Therefore, the total stress in equation (3) cannot be represented by the overburden stress. The detailed discussion about the determination of total stress in $\mathrm{CPB}$ is presented in the following section. 
2.2. Total Stress in $C P B$ under Arching Effect. To evaluate the total stress in $\mathrm{CPB}$ under arching effect, the force analysis of $\mathrm{CPB}$ structure is first conducted through limit equilibrium analysis. Then, the limit equilibrium analysis is used to derive the analytical model for the total stress in CPB. To perform the force analysis in $\mathrm{CPB}$ mass, a representative thin-layer CPB is selected from the fill mass. The relevant forces acting on the thin layer are plotted in Figure 2. It should be noted, since the constant material properties are assumed in this study, the spatial variation of material properties due to the different filling and curing conditions is neglected. Consequently, the selection of representative thin-layer CPB is dependent only on the position of local water table. Therefore, one representative layer is selected above water table to determine the total stress in the partially saturated zone, while the other representative layer is selected below the local water to derive the total stress in the fully saturated zone.

As shown in Figure 2, the forces acting on the representative thin layer can be classified into two categories including body force and surface forces. Specifically, the former refers to the self-weight load (i.e., $G_{\text {Срв}}$ ) due to the gravitational effect, and the latter consists of interface resistance force (i.e., interface shear force $F_{s}$ and interface adhesion force $F_{c}$ ) and the vertical forces acting on the top (i.e., $F_{v}$ ) and bottom (i.e., $F_{v}+d F_{v}$ ) surfaces of the $\mathrm{CPB}$ layer. In addition, the interface shear force (i.e., $F_{s}$ ) should be considered as a type of reaction force induced by the horizontal force (i.e., $F_{h}$ ) on the rock/CPB interface. Since the representative $\mathrm{CPB}$ layer is in equilibrium under the action of body force and surface forces, the equilibrium analysis approach can be utilized to derive the total vertical stress. Then, the horizontal stress can be calculated through reaction coefficient.

2.3. Total Stress in Unsaturated Zone. Based on the force analysis on the thin layer of $C P B$, the body force $G_{\mathrm{CPB}}$ in the unsaturated zone (i.e., $h<H_{\mathrm{wt}}$ ) can be expressed as follows:

$$
G_{\mathrm{CPB}}=\gamma_{\mathrm{CPBu}} L_{A} L_{B} \mathrm{~d} h,
$$

where $\gamma_{\mathrm{CPBu}}$ is the unit weight of unsaturated $\mathrm{CPB}, L_{A}$ and $L_{B}$, respectively, denote the length and width of the stope, and $\mathrm{d} h$ is the thickness of the representative thin layer.

In addition, the representative element is also subjected to the surface forces including the vertical stress on the top and bottom surface and the interface resistance force (i.e., the interface shear force and adhesion). The former (i.e., the vertical force $F_{V}$ ) can be calculated through the vertical stress $\sigma_{V}$ :

$$
F_{V}=\sigma_{v u} L_{A} L_{B} .
$$

For the interface resistance force, the interface friction component (i.e., $F_{\mathrm{As}}$ and $F_{\mathrm{Bs}}$ ) can be determined by the horizontal stress (i.e., $\sigma_{h \mathrm{Au}}$ and $\sigma_{h \mathrm{Bu}}$ ) and interface friction angle $\phi$ :

$$
\begin{aligned}
& F_{\mathrm{As}}=\sigma_{\mathrm{hAu}} L_{A} \tan \phi \mathrm{d} h, \\
& F_{\mathrm{Bs}}=\sigma_{\mathrm{hBu}} L_{B} \tan \phi \mathrm{d} h .
\end{aligned}
$$

The horizontal stress can be calculated by the product of vertical stress and the reaction coefficient $K$.

$$
\sigma_{\mathrm{hu}}=K \sigma_{\mathrm{vu}} \cdot
$$

Substituting equation (17) into equations (15) and (16), the interface shear force can be rewritten as follows:

$$
\begin{aligned}
& F_{\mathrm{As}}=\sigma_{\mathrm{vu}} K L_{A} \tan \phi \mathrm{d} h, \\
& F_{\mathrm{Bs}}=\sigma_{\mathrm{vu}} K L_{B} \tan \phi \mathrm{d} h .
\end{aligned}
$$

The interface adhesion force (i.e., $F_{\mathrm{Ac}}$ and $F_{\mathrm{Bc}}$ ) can be calculated as follows:

$$
\begin{aligned}
& F_{\mathrm{Ac}}=c L_{A} \mathrm{~d} h, \\
& F_{\mathrm{Bc}}=c L_{B} \mathrm{~d} h .
\end{aligned}
$$

where $c$ represents the rock/CPB interface adhesion.

To derive the analytical solution for the total vertical stress in the unsaturated zone of $\mathrm{CPB}$ mass, the force equilibrium equation in the vertical direction is utilized:

$$
G_{\mathrm{CPB}}=\mathrm{d} F_{V}+2\left(F_{\mathrm{As}}+F_{\mathrm{Ac}}\right)+2\left(F_{\mathrm{Bs}}+F_{\mathrm{Bc}}\right) .
$$

Then, substituting equations (13), (14), (18)-(21) into equation (22), the total vertical stress above the local water table $\left(h<H_{\mathrm{wt}}\right)$ can be solved by applying the initial condition (i.e., $\sigma_{\mathrm{vu}}=0$ when $h=0$ ):

$$
\sigma_{\mathrm{vu}}=\frac{\gamma_{\mathrm{CPBu}} L_{A} L_{B}-2 c\left(L_{A}+L_{B}\right)}{2 K \tan \phi\left(L_{A}+L_{B}\right)}\left\{1-\exp \left[-\frac{2 \tan \phi K\left(L_{A}+L_{B}\right)}{L_{A} L_{B}} h\right]\right\} \text {. }
$$

2.4. Total Stress in Fully Saturated Zone. Below the water table (i.e., $h \geq H_{\mathrm{wt}}$ ), similar force analysis can be conducted on a representative thin layer of $\mathrm{CPB}$. The body force (i.e., CPB gravity $G_{\mathrm{CPB}}$ ) in the fully saturated zone can be expressed as follows:

$$
G_{\mathrm{CPB}}=\gamma_{\mathrm{CPBs}} L_{A} L_{B} \mathrm{~d} h,
$$

where $\gamma_{\mathrm{CPBs}}$ is the unit weight of $\mathrm{CPB}$ in the fully saturated state.

In addition, the surface forces acting on the saturated thin layer can be determined in a similar way adopted in the unsaturated $\mathrm{CPB}$ layer. The vertical force $F_{V}$ can be expressed as follows:

$$
F_{V}=\sigma_{\mathrm{vs}} L_{A} L_{B} .
$$

with $\sigma_{\mathrm{vs}}$ as the vertical stress acting on the saturated thinlayer surface.

The rock/CPB interface resistance force (i.e., interface friction and adhesion forces) can be defined as follows: 


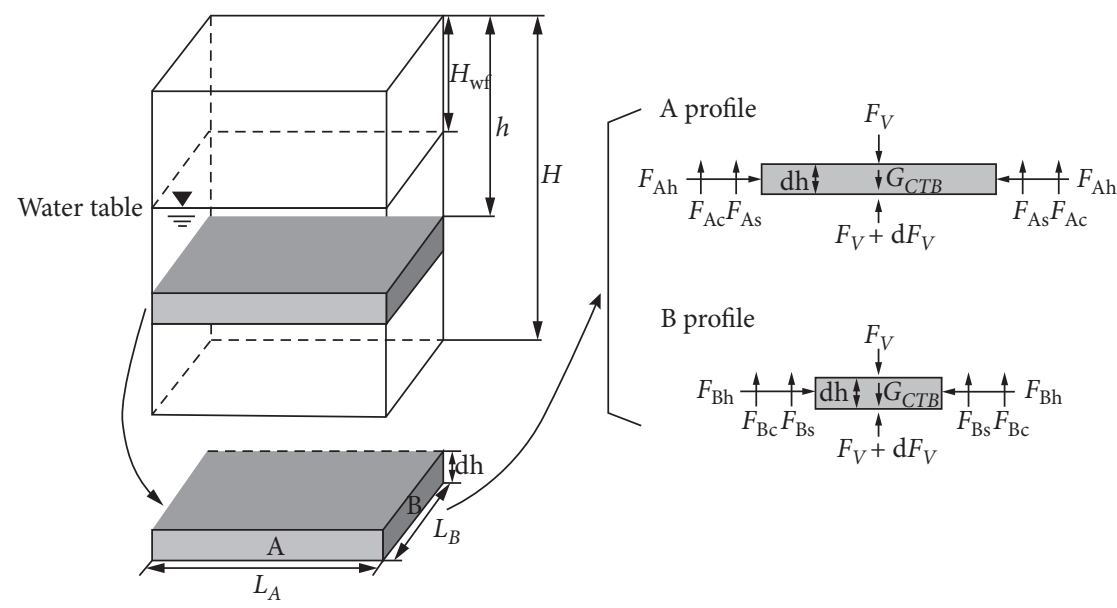

FIgURE 2: Force analysis in the unsaturated zone of CPB mass $\left(H_{\mathrm{wt}}\right.$ : local water table location, $h$ : thickness of $\mathrm{CPB}$ relative to top surface, $H$ : filling height, $L_{A}$ : longitudinal length of $\mathrm{CPB}$ mass, $L_{B}$ : transverse length of $\mathrm{CPB}$ mass, $\mathrm{d} h$ : thickness of the representative $\mathrm{CPB}$ layer, $F_{h}$ : horizontal force, $F_{v}$ : vertical force, $F_{c}$ : interface adhesion, $F_{s}$ : interface friction force, and $G_{\mathrm{CPB}}$ : self-weight load of CPB).

$$
\begin{aligned}
& F_{\mathrm{As}}=\sigma_{\mathrm{vs}} K L_{A} \tan \phi \mathrm{d} h, \\
& F_{\mathrm{Bs}}=\sigma_{\mathrm{vs}} K L_{B} \tan \phi \mathrm{d} h, \\
& F_{\mathrm{Ac}}=c L_{A} \mathrm{~d} h, \\
& F_{\mathrm{Bc}}=c L_{B} \mathrm{~d} h .
\end{aligned}
$$

Below the local water table (i.e., $h \geq H_{\mathrm{wt}}$ ), the force equilibrium equation in the vertical direction can be obtained by substituting equations (24)-(29) into equation (22). To derive the vertical stress in the saturated zone, the boundary condition on the top surface of local water table (i.e., $\left.h=H_{\mathrm{wt}}\right)$ is needed. The corresponding vertical stress can be expressed as follows:

$$
\begin{aligned}
\sigma_{v_{-} \mathrm{wt}}= & \frac{\gamma_{\mathrm{CPBS}} L_{A} L_{B}-2 c\left(L_{A}+L_{B}\right)}{2 K \tan \phi\left(L_{A}+L_{B}\right)} \\
& \left\{1-\exp \left[-\frac{2 K \tan \phi\left(L_{A}+L_{B}\right)}{L_{A} L_{B}} H_{\mathrm{wt}}\right]\right\} .
\end{aligned}
$$

Then, applying the initial condition (i.e., equation (30)), the total vertical stress in the saturated zone (i.e., $h>H_{\mathrm{wt}}$ ) can be derived through integrating equation:

$$
\begin{aligned}
\sigma_{\mathrm{vs}}= & \frac{\gamma_{\mathrm{CPBs}} L_{A} L_{B}-2 c\left(L_{A}+L_{B}\right)}{2 K \tan \phi\left(L_{A}+L_{B}\right)}\left\{1-\exp \left[-\frac{2 K \tan \phi\left(L_{A}+L_{B}\right)}{L_{A} L_{B}}\left(h-H_{w t}\right)\right]\right\}+\frac{\gamma_{\mathrm{CPBu}} L_{A} L_{B}-2 c\left(L_{A}+L_{B}\right)}{2 K \tan \phi\left(L_{A}+L_{B}\right)} \\
& \left\{1-\exp \left[-\frac{2 K \tan \phi\left(L_{A}+L_{B}\right)}{L_{A} L_{B}} H_{\mathrm{wt}}\right]\right\} .
\end{aligned}
$$

It should be noted that interface shear strength parameters (adhesion $c$ and friction angle $\phi$ ) adopted in equations (24) and (33) refer to the total stress shear strength parameters which can be measured through direct shear tests on rock/CPB samples. Since the Bishop effective stress (equation (11)) is adopted to define the effective stress in unsaturated (i.e., $\chi<1$ ) and fully saturated (i.e., $\chi=1$ ) zones, the effective shear strength parameters are not required in the present study.

2.5. 3D Effective Stress Model of CPB. The effective stress rather than total stress controls the mechanical behaviour of $\mathrm{CPB}$. Therefore, to characterize the variation of internal 
effective stress, a 3D effective stress model for CPB materials is needed, which can be derived by substituting equations
(23) and (31) to equation (11)) based on the definition of Bishop effective stress.

$$
\sigma^{\prime}= \begin{cases}\frac{\left(\gamma_{\mathrm{CPBu}} L_{A} L_{B}-2 c\left(L_{A}+L_{B}\right) / 2 K \tan \phi\left(L_{A}+L_{B}\right)\right)\left\{1-\exp \left[-\left(2 K \tan \phi\left(L_{A}+L_{B}\right) / L_{A} L_{B}\right) h\right]\right\}}{P_{e}^{R}}, & h \leq H_{\mathrm{wt}}, \\ \frac{\gamma_{\mathrm{CPBs}} L_{A} L_{B}-2 c\left(L_{A}+L_{B}\right)}{2 K \tan \phi\left(L_{A}+L_{B}\right)}\left\{1-\exp \left[-\frac{2 K \tan \phi\left(L_{A}+L_{B}\right)}{L_{A} L_{B}}\left(h-H_{\mathrm{wt}}\right)\right]\right\} & h>H_{\mathrm{wt}},\end{cases}
$$

with

$$
H_{\mathrm{wt}}=H\left[1-\exp \left(-\frac{v_{f} K_{b}}{W_{b}} \frac{l_{a} l_{b}}{L_{A} L_{B}} t\right)\right] .
$$

As indicated in equation (32), there exist a number of model parameters (including reaction coefficient $K$, WRC parameters $\alpha$ and $m$, interface friction angle $\phi$, adhesion $c$, and the coefficient of permeability $K_{b}$ ). The detailed discussion about the model parameters is provided in the Section of Determination of Model Parameters.

\section{Determination of Model Parameters}

To implement the developed 3D effective stress model (i.e., equation (32)), the associated model parameters are required. With respect to the components of the backfilling system, the associated model parameters can be divided into three groups including (1) CPB material properties, (2) rock/ $\mathrm{CPB}$ interface properties, and (3) properties related to barricade. The relevant discussion about determination of each group of model parameters is provided in the following subsections.

3.1. Rock/CPB Interface Properties. As aforementioned, the vertical stress is mainly affected by the rock/CPB interface shear force and adhesion. Correspondingly, the rock/CPB interface properties including interface friction angle $\phi$ and adhesion $c$ are required. In this regard, extensive experimental studies have been carried out [14, 34, 35]. The measured rock/CPB interface friction angle is listed in Table 1 . The obtained results indicate that the interface properties show no evident variation for each group of experimental data, which proves that the assumption of constant interface properties adopted in this study is reasonable. Hence, the average value of interface friction angle and adhesion from the collected data in Table 1 is used in this study, namely, $\phi=31.5^{\circ}$ and $c=14.2 \mathrm{kPa}$.

3.2. $C P B$ Material Properties. Apart from the rock/CPB interface properties, the total horizontal stress $\sigma_{h}$ is needed to calculate the interface friction force. The horizontal stress can be defined by the total vertical stress $\sigma_{v}$ and reaction coefficient $K$ (i.e., $\sigma_{h}=K \sigma_{v}$ ). Therefore, the reaction coefficient is required to assess the horizontal stress. During and after backfilling operation, the rock wall movement is expected to be small. For this reason, the reaction coefficient at rest $K_{r}$ (i.e., $K_{r}=1-\sin \varphi$ with $\varphi$ as the internal friction angle of $\mathrm{CPB}$ ) is adopted in this study. Moreover, previous studies $[14,34]$ showed that the internal friction angle of CPB $\varphi$ is almost equal to the rock/CPB interface friction angle $\phi$ (i.e., $\varphi=\phi)$. As discussed previously, the $\phi=31.5^{\circ}$ is adopted. Thus, the internal friction angle of CPB can be obtained, namely, $\varphi=31.5^{\circ}$. Compared with the measured data of $\varphi$ reported in the literature (see Table 2 ), $\varphi=31.5^{\circ}$ is reasonable for CPB materials.

To determine the water retention relationship, the WRC model parameters (i.e., $\alpha$ and $m$ ) are required. The parameter $\alpha$ is related to the inverse of air entry value $P_{e}$ (i.e., $\alpha=-\gamma_{w} / P_{e}$ with $\gamma_{w}$ as the unit weight of pore water). As aforementioned, the air entry value $P_{e}=-200 \mathrm{kPa}$ is adopted in this study. Hence, the parameter $\alpha=0.049 \mathrm{~m}^{-1}$ can be obtained. Compared with the reported values of $\alpha$ (i.e., $0.002 \mathrm{~m}^{-1}$ to $0.065 \mathrm{~m}^{-1}$ ) in Table 3, $\alpha=0.049 \mathrm{~m}^{-1}$ is a reasonable value and employed in this study. In addition, the dimensionless parameter $m$ is related to the width of the pore size distribution of solid particles [33]. Based on previous studies on WRCs of CPB (e.g., 30, 39, and 40), the parameter $m$ is in the range from 0.25 to 0.62 (see Table 3 ). Therefore, the average value $m=0.44$ is used in this study.

3.3. Material Property of Barricade. The CPB barricade can be constructed by various materials (e.g., porous brick, concrete, timber frame, shotcrete, and so on). However, to avoid excessive PWP acting on the barricade structure, the permeable concrete barricade bricks are commonly adopted to construct the barricade in practice $[41,42]$. The measured data of coefficient of permeability of the concrete brick (i.e., $K_{b}$ ) are normally in the range of $0.03 \mathrm{~cm} / \mathrm{s}$ to $0.31 \mathrm{~cm} / \mathrm{s}$ (see Table 4). Therefore, the average value of $K_{b}=0.17 \mathrm{~cm} / \mathrm{s}$ is employed in the present study.

As shown in equation (5), the constant scaling parameter $v_{f}$ is required for the definition of movement velocity of local water table $v_{\mathrm{wt}}$. In this study, the constant scaling 
TABLE 1: Measured data of interface friction angle and adhesion.

\begin{tabular}{lccc}
\hline Data source & Nasir and Fall [14] & Koupouli et al. [34] & Fall and Nasir [35] \\
\hline Interface friction angle $\left(^{\circ}\right)$ & $20 \sim 30$ & $38 \sim 40$ & $28 \sim 34$ \\
Interface adhesion $(\mathrm{kPa})$ & $25 \sim 30$ & $8 \sim 9$ & $3.2 \sim 10.2$ \\
\hline
\end{tabular}

TABLE 2: Measured data of internal friction angle of CPB.

\begin{tabular}{lccc}
\hline Data source & Cui and Fall [36] & Koupouli et al. [34] & Ghirian and Fall [37] \\
\hline Internal friction angle $\left(^{\circ}\right)$ & $39 \sim 45$ & $27 \sim 44$ & $40 \sim 55$ \\
\hline
\end{tabular}

TABLE 3: Comparison of WRC model parameters collected from the literature.

\begin{tabular}{lcc}
\hline Data source & $\alpha\left(\mathrm{m}^{-1}\right)$ & $m(-)$ \\
\hline Abdul-Hussain and Fall [30] & $0.008 \sim 0.041$ & $0.3 \sim 0.47$ \\
Cui and Fall [38] & $0.002 \sim 0.065$ & $0.41 \sim 0.45$ \\
Benson et al. [39] & $0.006 \sim 0.057$ & $0.25 \sim 0.52$ \\
Suazo [40] & $0.002 \sim 0.013$ & $0.38 \sim 0.62$ \\
\hline
\end{tabular}

-: dimensionless unit.

TABLE 4: Measured data of coefficient of permeability of concrete brick used for barricade.

\begin{tabular}{lc}
\hline Data source & Coefficient of permeability $(\mathrm{cm} / \mathrm{s})$ \\
\hline Sivakugan et al. [41] & $0.10 \sim 0.31$ \\
Berndt et al. [43] & $0.03 \sim 0.30$ \\
Rankine [42] & $0.10-0.19$ \\
\hline
\end{tabular}

parameter is defined in terms of the ratio of coefficient of permeability of $\mathrm{CPB}$ and barricade (i.e., $v_{f}=K_{\mathrm{CРB}} / K_{b}$ ). In this study, the initial coefficient of permeability is assumed to be equal to the counterpart of tailings. The measured data of coefficient of permeability of tailings are listed in Table 5, and the average value of coefficient of permeability of fresh СРВ $K_{\text {СРв } 0}=3.4 \times 10^{-4} \mathrm{~cm} / \mathrm{s}$ is obtained. As discussed previously, the average value of $K_{b}=0.17 \mathrm{~cm} / \mathrm{s}$ is adopted in this study. Therefore, the scaling parameter $v_{f}=2 \times 10^{-3}$ is used in this study.

\section{Sensitivity Analyses}

The material parameters adopted in the developed model may change from mine to mine. Therefore, it is necessary to conduct the sensitivity analysis to analyze the uncertainties induced by the variation of model parameters. In this study, the effect of interface friction angle $\phi$ (i.e., the rock/CPB interface property) and the coefficient of permeability of barricade $K_{b}$ (i.e., the property of barricade) were investigated. To clearly demonstrate the effect of investigated parameters on the internal stress in $\mathrm{CPB}$, a control stope is selected as a reference. The dimensions of stope and barricade and filling strategies and rate adopted in the control stope are listed Table 6. The model parameters listed in Table 7 are employed for the control stope. The monitoring point is located at the stope floor.

For the model implementation, the backfilling rate will be used to calculate the present filling height, $H$, based on equation (7). It should be noted that multiple filling sequences may be adopted in the stopes. Correspondingly, the rest time
TABLE 5: Measured data of coefficient of permeability of tailings.

\begin{tabular}{lc}
\hline Data source & Coefficient of permeability $\left(10^{-4} \mathrm{~cm} / \mathrm{s}\right)$ \\
\hline Aubertin et al. [44] & $0.5 \sim 4$ \\
Xu et al. [45] & $3.0 \sim 5.6$ \\
Banks and Kirkham [46] & $2.2 \sim 4.7$ \\
\hline
\end{tabular}

TABLE 6: Backfilling conditions adopted in the control stope for sensitivity analysis.

\begin{tabular}{lc}
\hline Parameters & Control stope \\
\hline Length of stope $L_{A}(\mathrm{~m})$ & 15 \\
Width of stope $L_{B}(\mathrm{~m})$ & 7.5 \\
Height of stope $H(\mathrm{~m})$ & 36 \\
Filling rate $(\mathrm{m} / \mathrm{d})$ & 12 \\
Filling strategy & Continuous filling \\
Width of barricade $l_{a}(\mathrm{~m})$ & 6 \\
Height of barricade $l_{b}(\mathrm{~m})$ & 6 \\
Thickness of barricade $W_{b}(\mathrm{~m})$ & 0.3 \\
\hline
\end{tabular}

$\left(t_{\mathrm{ri}}\right)$ is considered at the end of each filling sequence, and filling height will be kept constant during each rest time $t_{\mathrm{ri}}$. Hence, the piece-wise function (equation (7)) can be used to capture the backfilling strategy used in practice. After the backfilling height is obtained, the evolution of local water table, $H_{\mathrm{wt}}$, will be quantitatively evaluated by equation (8). As indicated in equation (8), the local water table will change its spatial position as time elapses, which is used to capture the water loss due to the water drainage. When the filling height, $H$, and local water table position, $H_{\mathrm{wt}}$, are determined, the corresponding total stress, pwp, and effective stress can be calculated by equation (32). Therefore, the proposed model is able to analytically describe the spatiotemporal evolution of internal stresses in CPB. Then, the proposed model was implemented to perform the sensitivity analysis and model application.

4.1. Interface Friction Angle. The interface friction angle $\phi$ can directly contribute to the development of interface shear stress between $\mathrm{CPB}$ mass and surrounding rock and thus affect the internal stress in CPB. In this study, three different interface friction angles including $25^{\circ}, 31.5^{\circ}$, and $40^{\circ}$ were chosen. The development of internal stress in $\mathrm{CPB}$ with different interface friction angles is plotted in Figure 3. From this figure, it can be found that the internal stress is sensitive to the change of interface friction angle and thus to the interaction between $\mathrm{CPB}$ and rock walls. With the increase in interface friction angle, a decrease in effective stress was observed. This is because larger interface friction angle can 
TABLE 7: Model parameters adopted for sensitivity analysis and model application.

\begin{tabular}{lcc}
\hline Type of model parameters & Model parameters & Value \\
\hline \multirow{2}{*}{ Interface properties } & Interface friction angle $\phi\left(^{\circ}\right)$ & 31.5 \\
& Interface adhesion $c(\mathrm{kPa})$ & 14.2 \\
\hline & Internal friction angle $\varphi\left(^{\circ}\right)$ & 31.5 \\
& Reaction coefficient $K(-)$ & 0.27 \\
CPB material properties & Parameter of the WRC model $\alpha\left(\mathrm{m}^{-1}\right)$ & 0.049 \\
& Parameter of the WRC model $m(-)$ & 0.44 \\
& Air entry value of CPB $P_{e}(\mathrm{kPa})$ & -0.55 \\
& Fitting parameter of effective stress $R(-)$ & 18 \\
\hline Barricade parameter & Saturated unit weight of CPB $\gamma_{\mathrm{CPBs}}\left(\mathrm{kN} / \mathrm{m}^{3}\right)$ & 14 \\
\hline
\end{tabular}

Symbol “_” indicates dimensionless unit.

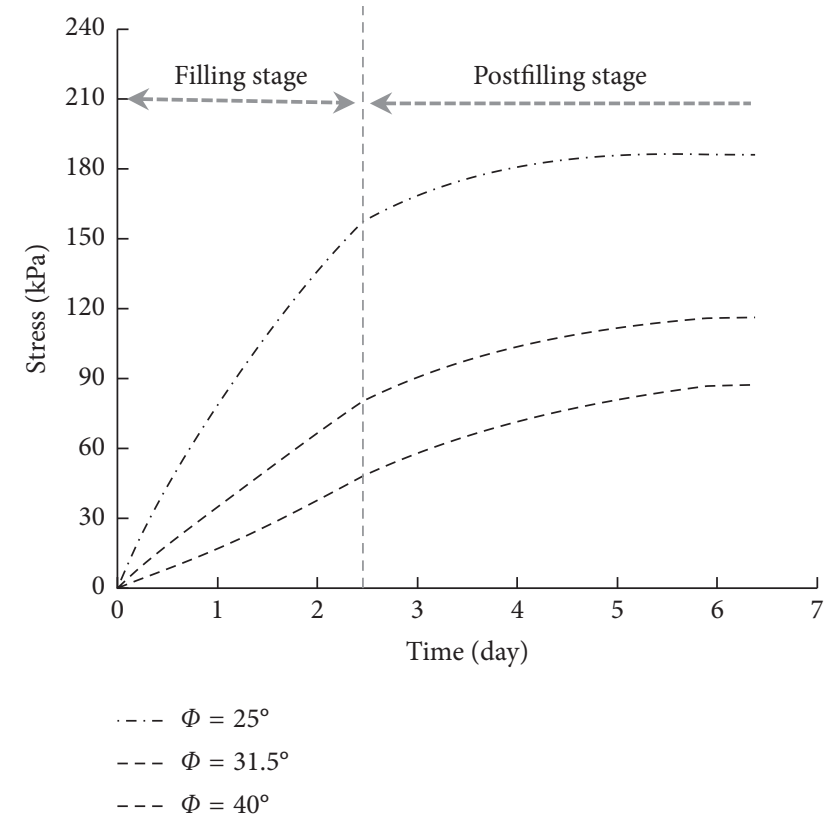

FIgURE 3: Variation of effective stress in CPB with different interface friction angles.

cause higher interface shear stress and thus, to a larger extent, reduce the internal stress in CPB (i.e., strengthen the arching effect).

4.2. Coefficient of Permeability of Barricade. Water drainage through barricade structure causes the variation of PWP and thus affects the effective stress in CPB. Correspondingly, coefficient of permeability $K_{b}$ plays a crucial role in the process of barricade drainage. Therefore, it is necessary to investigate the effect of $K_{b}$ on the variation of internal stress in CPB. In this study, a range of coefficient of permeability including $0.2 \mathrm{~cm} / \mathrm{s}, 0.17 \mathrm{~cm} / \mathrm{s}$, and $0.14 \mathrm{~cm} / \mathrm{s}$ were selected. As shown in Figure 4, the effective stress demonstrates an increasing trend with the increase in $K_{b}$. This is because higher value of $K_{b}$ can enhance the barricade drainage and thus reduce the PWP to a larger extent. Consequently, a higher effective stress was observed in $\mathrm{CPB}$ with a larger value of $K_{b}$.

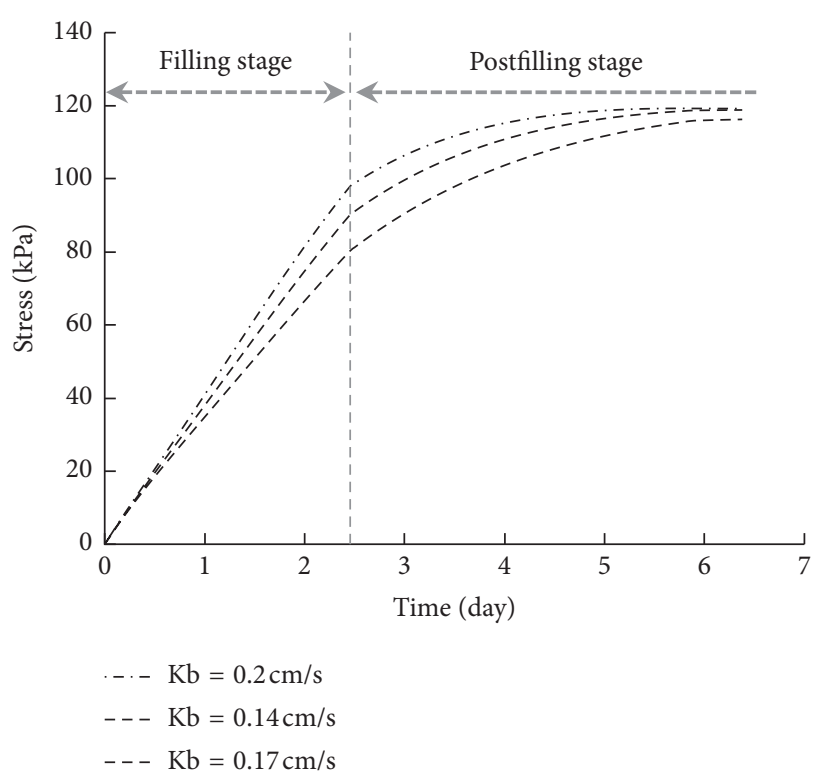

FIGURE 4: Variation of effective stress in CPB with different coefficient of permeability of barricade.

4.3. Model Application. Due to the irregularities of ore bodies, various mining methods, and backfilling strategies, the resultant backfilling conditions may differ from mine to mine [38]. Hence, the developed model was used to address the practical problems including the effects of operation time, stope geometry, and rock/CPB interface properties on the internal stress in $\mathrm{CPB}$. To clearly demonstrate the effects of factors investigated in the following subsections, a control stope is chosen as a reference. All investigations are conducted through some specific adjustments to the control stope. The model parameters listed in Table 7 are employed for the control stope. The dimensions of stope and barricade and filling strategies and rate adopted in the control stope are listed Table 8. The monitoring point is located at the stope floor.

4.4. Effect of Operation Time. Due to staged placement of $\mathrm{CPB}$ into stope and drainage through barricade, the internal stress (effective stress, total stress, and PWP) can 
TABLE 8: Backfilling conditions adopted in the control stope.

\begin{tabular}{lc}
\hline Parameters & Control stope \\
\hline Length of stope $L_{A}(\mathrm{~m})$ & 15 \\
Width of stope $L_{B}(\mathrm{~m})$ & 7.5 \\
Height of stope $H(\mathrm{~m})$ & 36 \\
Filling rate $(\mathrm{m} / \mathrm{d})$ & 12 \\
Filling strategy & Two-stage filling with 1-day rest \\
Width of barricade $l_{a}(\mathrm{~m})$ & time \\
Height of barricade $l_{b}(\mathrm{~m})$ & 6 \\
Thickness of barricade & 6 \\
$W_{b}(\mathrm{~m})$ & 0.3 \\
\hline
\end{tabular}

demonstrate strongly time-dependent characteristics [2, 47]. As indicated in equation (32), the developed model incorporates the evolution of PWP (including both positive and negative PWP) and total stress (i.e., different unit weight of $\mathrm{CPB}$ in saturated and unsaturated states) into the prediction of effective stress in $\mathrm{CPB}$. Hence, the variation of effective stress with time can be described by the developed model. In this study, the control stope is chosen to assess the change of internal stress in $\mathrm{CPB}$ with time. The evolution of internal stress in CPB is plotted in Figure 5. From this figure, it can be observed that (1) the effective stress gradually increases during the filling stage and postfilling stage, which is mainly attributed to the increase in total vertical stress with the fresh $\mathrm{CPB}$ poured into stope and to the water drainage through barricade and (2) during the rest period (from 1 day to 2 days), the effective stress shows an increasing trend although no fresh $\mathrm{CPB}$ is placed into stope during this stage. This is because of the pore-water loss by barricade drainage. As shown in Figure 5, the PWP decreases from $86 \mathrm{kPa}$ to $64 \mathrm{kPa}$ during the rest period, which contributes to the enhancement of effective stress in CPB. Therefore, the staged filling operation with a specified rest time is favorable to the improvement of stability of CPB structure. The obtained results indicate that the developed model is able to describe the change of internal stress in CPB with operation time.

Moreover, due to the water drainage through barricade, negative PWP will be generated in CPB. Therefore, it is necessary to investigate the spatial distribution of PWP in CPB with operation time. The comparison of PWP versus stope height for different operation time is plotted in Figure 6. From this figure, it can be observed that during the filling stage (from 0 to 4 days), the PWP shows an increase for a given stope elevation. As discussed previously, this is due to the continuous placement of fresh CPB into stope. Moreover, the location of water table also increases with time during the filling stage. However, the PWP shows an opposite trend during the postfilling stage. Specifically, PWP becomes more negative for a given elevation, and the water table decreases with time. Therefore, the obtained results indicate that filling operation and water drainage through barricade can significantly affect the distribution of PWP in CPB. The developed model is able to characterize the spatial evolution of PWP in CPB.

4.5. Effect of Stope Geometry. As aforementioned, the stope geometry may differ from one stope to another due to the irregularities of ore body and various stoping methods. To

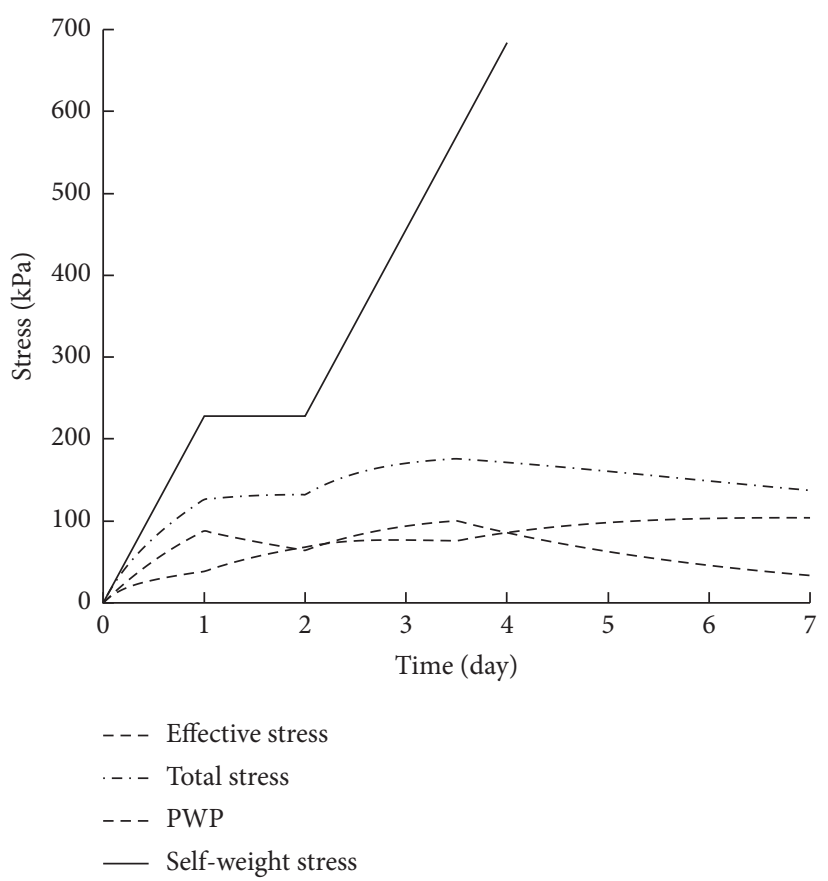

FIGURE 5: Effect of operation time on the variation of internal stress in $\mathrm{CPB}$.

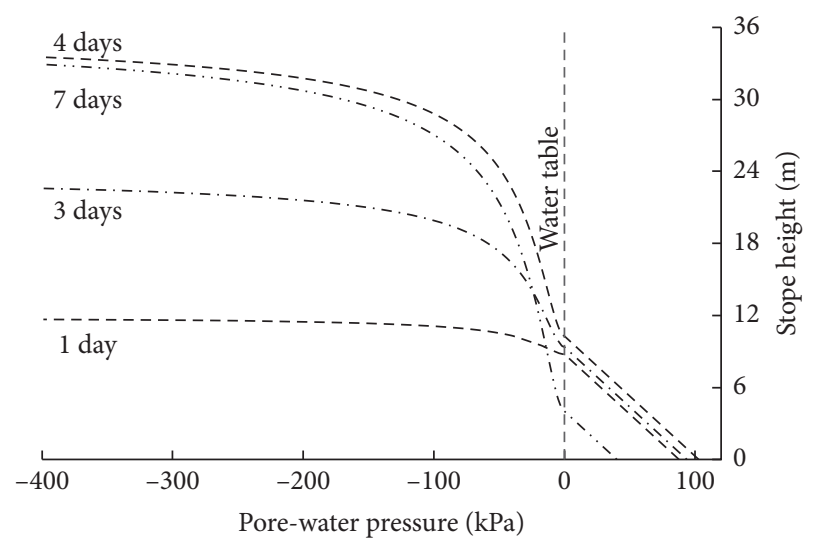

FIGURE 6: PWP versus stope height for different operation times.

investigate the effect of stope geometry, three different stope heights including $15 \mathrm{~m}, 30 \mathrm{~m}$, and $45 \mathrm{~m}$ were selected. In this case, the values of model parameters are same to those adopted in control stope. Figure 7 presents the development of internal stress for different stope heights. The results show, as expected, that stope height (i.e., the backfilling heights) has a significant effect on the variation of internal stress in CPB. Specifically, a higher level of effective stress is obtained in the CPB with a higher stope height (see Figure $7(\mathrm{a})$ ) after the filling completion. This is due to the larger total stress developed in $\mathrm{CPB}$ with higher filling height (see Figure 7(b)). However, the contribution of filling height to effective stress becomes progressively smaller with the increase in stope height. For example, at the end of filling operation in these three stopes, the effective stress for $30 \mathrm{~m}$ and $45 \mathrm{~m}$ cases, respectively, increases by $40 \%(163 \mathrm{kPa})$ and 


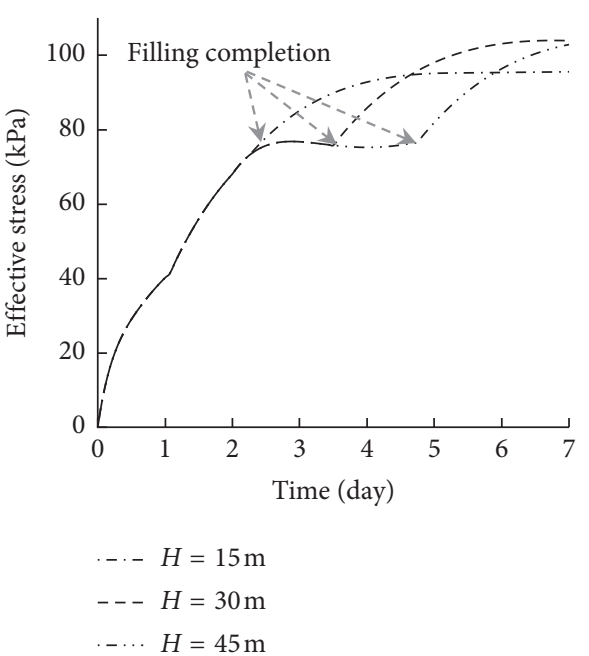

(a)

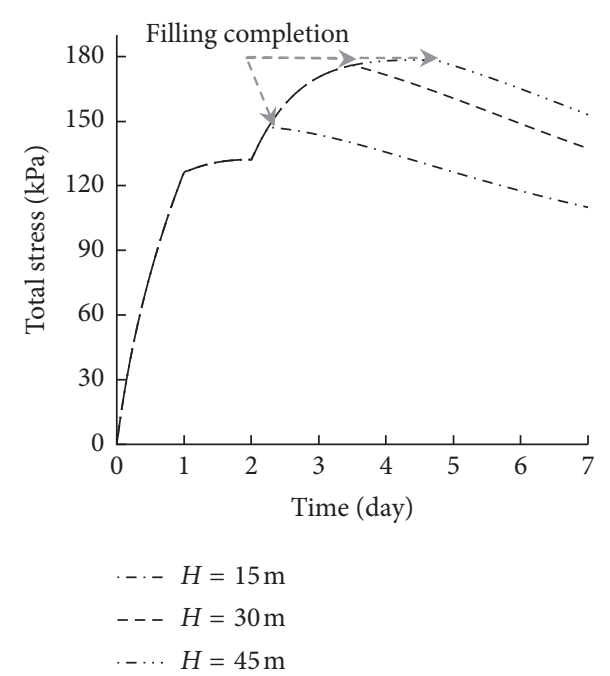

(b)

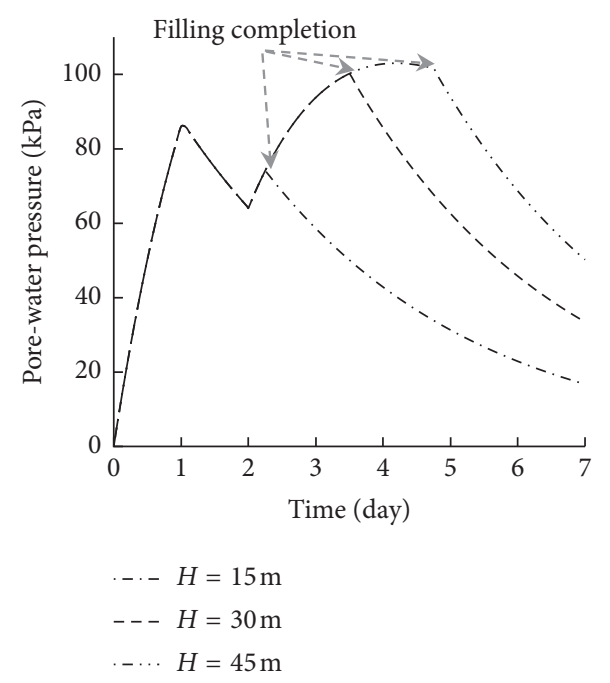

(c)

FIGURE 7: Effect of stope geometry on the variation of internal stress: (a) effective stress; (b) total stress; (c) PWP.

$52 \%(178 \mathrm{kPa})$ with respect to the counterpart $(117 \mathrm{kPa})$ obtained in stope with a height of $15 \mathrm{~m}$. This is partly because the arching effect can reduce the total stress to a larger extent for CPB with higher height and partly because higher PWP is observed after filling operation for higher filling height case (see Figure $7(\mathrm{c})$ ). The increased PWP can reduce the development of effective stress and thus further contribute to the nonlinear variation of effective stress in $\mathrm{CPB}$. The obtained results are consistent with the previous study [38] on the variation of internal stress in $\mathrm{CPB}$.

4.6. Effect of Rock/CPB Interface Adhesion. Due to the rock/ $\mathrm{CPB}$ interface resistance, the resultant total vertical stress in $\mathrm{CPB}$ is less than its self-weight stress, namely, the arching effect is attributed to the interface interaction. The rock/CPB interface interaction consists of two components including interface friction stress and adhesion. From a mathematical point of view, the contribution of interface friction angle and adhesion to the arching effect is same. Hence, only the interface adhesion $c$ is selected to investigate the effect of rock/CPB interface interaction on the internal stress in CPB. For this purpose, a range of interface adhesion values: $10 \mathrm{kPa}, 15 \mathrm{kPa}$, and $20 \mathrm{kPa}$ were chosen in this study. The comparison of internal stress in $\mathrm{CPB}$ with different interface adhesion is presented in Figure 8 . It can be observed that lower total stress is obtained in $\mathrm{CPB}$ with higher interface adhesion (see Figure 8(a)), namely, the arching effect is enhanced by the increased interface adhesion. Moreover, it should be noted that as indicated in equation (32), the interface adhesion only affects total stress, which means the resultant PWP is same for these three cases. Consequently, with the change of interface adhesion, the development of effective stress is dominated by the variation of total stress. Hence, the lower total stress can reduce the level of effective stress in CPB (Figure 8(b)). The obtained results show that the change of interface adhesion can significantly affect the internal stress in CPB. Therefore, the interface interaction 


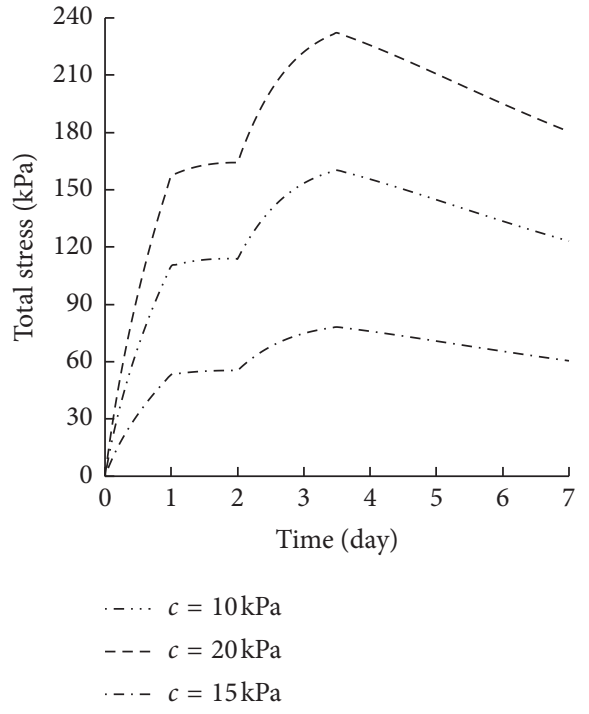

(a)

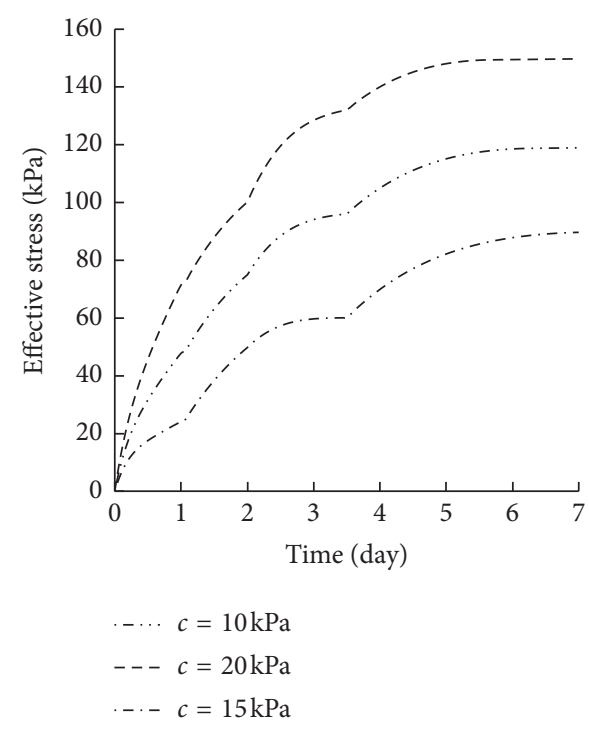

(b)

FIgURE 8: Effect of interface adhesion on the development of (a) total stress and (b) effective stress.

should be incorporated into the optimal design of $\mathrm{CPB}$ structure.

\section{Discussion}

As complex reactive porous media, the behaviour and performance of CPB are strongly affected by arching effect [48], curing conditions (e.g., temperature of surrounding rock and water drainage) [49], mix recipe (cement content, tailings types, and water-to-cement ratio) [50], and backfilling operation (filling rate and sequences) [51]. The focus of the present study is on the effect of rock/CPB interface behaviour on the internal stresses. The analytical model (equation (32)) was developed based on limit equilibrium analysis and several assumptions (including constant material properties and uniformly distributed stresses in the horizontal direction). Therefore, it is necessary to identify the associated limitations of the developed model for its engineering application and future study.

First, constant material properties are assumed in the present study. Therefore, this model is not applicable for the prediction of internal stresses under the effects of (1) binder hydration on the improvement of material properties such as the CPB cohesion and interface adhesion and (2) volume change on the porosity-dependent material properties such as hydraulic conductivity and associated development of excess PWP in CPB. Second, to perform equilibrium analysis on the representative thin-layer $\mathrm{CPB}$, uniformly distributed stresses (total stress, effective stress, and PWP) are assumed in the horizontal direction. However, due to differential settlement [52] and the rock/CTB interface interaction [38] in $\mathrm{CPB}$, especially for the $\mathrm{CPB}$ in narrow stope, the nonuniform distribution of internal stresses may develop in $\mathrm{CPB}$ mass. Consequently, the proposed model (equation (32)) may overestimate the arching effect in stopes. Third, it is assumed that the change of PWP is attributed to the water drainage through the barricade. However, there exist several additional contributors (e.g., water consumption by binder hydration, water evaporation through top surface of $C P B$, and water exchange between $\mathrm{CPB}$ and fractured rock walls) to the variation of PWP in the field [51]. Consequently, the obtained results from this equation (10) may underestimate the change of PWP in CTB. The abovementioned aspects will require more work related to advanced mathematical modelling (especially the multiphysics modelling) for the reactive $\mathrm{CPB}$.

\section{Conclusions}

Based the limit equilibrium analysis, a new 3D analytical solution was developed to predict the internal stresses (total stress, effective stress, and PWP) under the influence of rock/ $\mathrm{CPB}$ interface interaction. In this model, the changes of the saturation state in $\mathrm{CPB}$ due to the water drainage through barricade and rock/CPB interface behaviour were taken into account. The model parameters were determined in terms of measurable model parameters. The uncertainties induced by model parameters were assessed by the sensitivity analysis. Moreover, the developed model was applied to address the practical problems including the effects of operation time, stope geometry, and rock/CPB interface properties on the internal stress in CPB. Based on the obtained results in the present study, the following conclusions were drawn:

(1) A 3D effective stress model is developed in this study to assess the evolution of internal stress in CPB. The model fully considers the influence of rock/CPB interface interaction, backfilling conditions, and barricade drainage.

(2) The variation of internal stress (effective stress, total stress, and PWP) in CPB can demonstrate strongly nonlinear and time-dependent characteristics. 
(3) The effect of stope geometry on the total stress becomes progressively weak with the increase in filling height, which can further affect the enhancement of effective stress in $\mathrm{CPB}$ and thus its stability.

(4) The rock/CPB interaction significantly affects the arching effect and thus the variation of internal stress in CPB. The obtained results show that the total stress and effective stress are sensitive to the change of interface adhesion. With the increase in interface adhesion, the arching can develop to a larger extent.

(5) The reaction coefficient can affect the interface shear stress and thus the internal stress in CPB. The decreased reaction coefficient can reduce the contribution of interface shear stress to the arching effect.

The proposed analytical model can be used as a helpful tool to assess the effects of interaction between CPB mass and surrounding rock, backfilling conditions (e.g., filling strategies and stope geometry), and drainage conditions for both filling and postfilling stages. Hence, the developed model can be employed as an effective tool for the optimal design of CPB structure.

\section{Data Availability}

The data used to support the findings of this study are available from the corresponding author upon request.

\section{Conflicts of Interest}

The authors declare that they have no conflicts of interest regarding the publication of this paper.

\section{Acknowledgments}

This study was funded by the Natural Sciences and Engineering Research Council of Canada (NSERC) Discovery grant, the Shaanxi Natural Science Foundation (grant no. 2019JQ-756), the Special Scientific Research Project of Shaanxi Education Department (grant no. 19JK0452), and the China Postdoctoral Science Foundation (grant no. 2019M663648).

\section{References}

[1] E. Yilmaz, T. Belem, B. Bussière, M. Mbonimpa, and M. Benzaazoua, "Curing time effect on consolidation behaviour of cemented paste backfill containing different cement types and contents," Construction and Building Materials, vol. 75, pp. 99-111, 2015.

[2] L. Cui and M. Fall, "An evolutive elasto-plastic model for cemented paste backfill," Computers and Geotechnics, vol. 71, pp. 19-29, 2016.

[3] W. Li and M. Fall, "Sulphate effect on the early age strength and self-desiccation of cemented paste backfill," Construction and Building Materials, vol. 106, pp. 296-304, 2016.

[4] E. Yilmaz and M. Fall, Paste Tailings Management, Springer International, Berlin, Germany, 2017.

[5] I. L. S. Libos and L. Cui, "Effects of curing time, cement content, and saturation state on mode-I fracture toughness of cemented paste backfill," Engineering Fracture Mechanics, vol. 235, p. 107174, 2020.

[6] T. Yilmaz, B. Ercikdi, and H. Deveci, "Utilisation of construction and demolition waste as cemented paste backfill material for underground mine openings," Journal of Environmental Management, vol. 222, pp. 250-259, 2018.

[7] Y. Wang, Y. Cao, L. Cui, Z. Si, and H. Wang, "Effect of external sulfate attack on the mechanical behavior of cemented paste backfill," Construction and Building Materials, vol. 263, p. 120968, 2020.

[8] T. Yılmaz, B. Ercikdi, and F. Cihangir, "Evaluation of the neutralization performances of the industrial waste products (IWPs) in sulphide-rich environment of cemented paste backfill," Journal of Environmental Management, vol. 258, p. 110037, 2020.

[9] T. Yilmaz, B. Ercikdi, and H. Deveci, "Evaluation of geochemical behaviour of flooded cemented paste backfill of sulphide-rich tailings by dynamic-tank leaching test," International Journal of Mining, Reclamation and Environment, pp. 1-20, 2020.

[10] L. Cui and M. Fall, "A coupled thermo-hydro-mechanicalchemical model for underground cemented tailings backfill," Tunnelling and Underground Space Technology, vol. 50, pp. 396-414, 2015.

[11] G. Lu, M. Fall, and L. Cui, "A multiphysics-viscoplastic cap model for simulating blast response of cemented tailings backfill," Journal of Rock Mechanics and Geotechnical Engineering, vol. 9, no. 3, pp. 551-564, 2017.

[12] M. Kermani, F. P. Hassani, E. Aflaki, M. Benzaazoua, and M. Nokken, "Evaluation of the effect of sodium silicate addition to mine backfill, Gelfill - Part 2: effects of mixing time and curing temperature," Journal of Rock Mechanics and Geotechnical Engineering, vol. 7, no. 6, pp. 668-673, 2015.

[13] B. Ercikdi, H. Baki, and M. İzki, "Effect of desliming of sulphide-rich mill tailings on the long-term strength of cemented paste backfill," Journal of Environmental Management, vol. 115, pp. 5-13, 2013.

[14] O. Nasir and M. Fall, "Shear behaviour of cemented pastefillrock interfaces," Engineering Geology, vol. 101, no. 3-4, pp. 146-153, 2008.

[15] N. El Mkadmi, M. Aubertin, and L. Li, "Effect of drainage and sequential filling on the behavior of backfill in mine stopes," Canadian Geotechnical Journal, vol. 51, no. 1, pp. 1-15, 2013.

[16] E. Yilmaz, T. Belem, and M. Benzaazoua, "Effects of curing and stress conditions on hydromechanical, geotechnical and geochemical properties of cemented paste backfill," Engineering Geology, vol. 168, pp. 23-37, 2014.

[17] S. Cao, W. Song, and E. Yilmaz, "Influence of structural factors on uniaxial compressive strength of cemented tailings backfill," Construction and Building Materials, vol. 174, pp. 190-201, 2018.

[18] J. Fu, W. Song, and Y. Tan, "Study on microstructural evolution and strength growth and fracture mechanism of cemented paste backfill," Advances in Materials Science and Engineering, vol. 2016, Article ID 8792817, 13 pages, 2016.

[19] J. Wu, M. Feng, G. Han, X. Ni, and Z. Chen, "Experimental investigation on mechanical properties of cemented paste backfill under different gradations of aggregate particles and types and contents of cementing materials," Advances in Materials Science and Engineering, vol. 2019, Article ID 9456861, 11 pages, 2019.

[20] S. Cao and W.-d. Song, "Effect of filling interval time on longterm mechanical strength of layered cemented tailing 
backfill," Advances in Materials Science and Engineering, vol. 2016, 2016.

[21] M. Helinski, M. Fahey, and A. Fourie, "Behavior of cemented paste backfill in two mine stopes: measurements and modeling," Journal of Geotechnical and Geoenvironmental Engineering, vol. 137, no. 2, pp. 171-182, 2010.

[22] J. P. Doherty, A. Hasan, G. H. Suazo, and A. Fourie, "Investigation of some controllable factors that impact the stress state in cemented paste backfill," Canadian Geotechnical Journal, vol. 52, no. 12, pp. 1901-1912, 2015.

[23] P. Yang, L. Li, and M. Aubertin, "A new solution to assess the required strength of mine backfill with a vertical exposure," International Journal of Geomechanics, vol. 17, no. 10, Article ID 04017084, 2017.

[24] L. Li, "Generalized solution for mining backfill design," International Journal of Geomechanics, vol. 14, no. 3, Article ID 04014006, 2014.

[25] M. Soltani and K. Maekawa, "Numerical simulation of progressive shear localization and scale effect in cohesionless soil media," International Journal of Non-linear Mechanics, vol. 69, pp. 1-13, 2015.

[26] L. Cui, "M. Fall, "Multiphysics model for consolidation behavior of cemented paste backfill," International Journal of Geomechanics, vol. 17, no. 3, Article ID 04016077, 2016.

[27] A. W. Bishop, "The principle of effective stress," Teknisk Ukeblad, vol. 106, no. 39, pp. 859-863, 1955.

[28] I. Vlahinić, H. M. Jennings, J. E. Andrade, and J. J. Thomas, "A novel and general form of effective stress in a partially saturated porous material: the influence of microstructure," Mechanics of Materials, vol. 43, no. 1, pp. 25-35, 2011.

[29] N. Khalili and M. Khabbaz, "A unique relationship for chi for the determination of the shear strength of unsaturated soils," Geotechnique, vol. 52, no. 1, pp. 76-77, 2002.

[30] N. Abdul-Hussain and M. Fall, "Unsaturated hydraulic properties of cemented tailings backfill that contains sodium silicate," Engineering Geology, vol. 123, no. 4, pp. 288-301, 2011.

[31] D. G. Fredlund and H. Rahardjo, Soil Mechanics for Unsaturated Soils, John Wiley \& Sons, Hoboken, NJ, USA, 1993.

[32] L. Cui and M. Fall, "Numerical simulation of consolidation behavior of large hydrating fill mass," International Journal of Concrete Structures and Materials, vol. 14, no. 23, pp. 1-16, 2020.

[33] M. T. Van Genuchten, "A closed-form equation for predicting the hydraulic conductivity of unsaturated soils," Soil Science Society of America Journal, vol. 44, no. 5, pp. 892-898, 1980.

[34] N. J. F. Koupouli, T. Belem, P. Rivard, and H. Effenguet, "Direct shear tests on cemented paste backfill-rock wall and cemented paste backfill-backfill interfaces," Journal of Rock Mechanics and Geotechnical Engineering, vol. 8, no. 4, pp. 472-479, 2016.

[35] M. Fall and O. Nasir, "Mechanical behaviour of the interface between cemented tailings backfill and retaining structures under shear loads," Geotechnical and Geological Engineering, vol. 28, no. 6, pp. 779-790, 2010.

[36] L. Cui and M. Fall, "Mechanical and thermal properties of cemented tailings materials at early ages: influence of initial temperature, curing stress and drainage conditions," Construction and Building Materials, vol. 125, pp. 553-563, 2016.

[37] A. Ghirian and M. Fall, "Coupled thermo-hydro-mechanicalchemical behaviour of cemented paste backfill in column experiments," Engineering Geology, vol. 170, pp. 11-23, 2014.
[38] L. Cui and M. Fall, "Multiphysics modeling of arching effects in fill mass," Computers and Geotechnics, vol. 83, pp. 114-131, 2017.

[39] C. Benson, G. Bohnhoff, P. Apiwantragoon et al., "Comparison of model predictions and field data for an ET cover," in Proceedings of Tailings And Mine Waste, Vail, Colorado, USA, November 2004.

[40] G. H. Suazo, "Effects of Dynamic Loading on the Geomechanical Behaviour of Cemented Paste Backfill," Ph.D. Thesis, University of Western Australia, Perth, Austrailia, 2016.

[41] N. Sivakugan, R. Rankine, K. Rankine, and K. Rankine, "Geotechnical considerations in mine backfilling in Australia," Journal of Cleaner Production, vol. 14, no. 12-13, pp. 1168-1175, 2006.

[42] K. J. Rankine, "An Investigation into the Drainage Characteristics and Behaviour of Hydraulically Placed Mine Backfill and Permeable Minefill Barricades," Ph.D. thesis, James Cook University, Queensland, Australia, 2005.

[43] C. C. Berndt, K. J. Rankine, and N. Sivakugan, "Materials properties of barricade bricks for mining applications," Geotechnical and Geological Engineering, vol. 25, no. 4, pp. 449-471, 2007.

[44] M. Aubertin, B. Bussiere, and R. P. Chapuis, "Hydraulic conductivity of homogenized tailings from hard rock mines," Canadian Geotechnical Journal, vol. 33, no. 3, pp. 470-482, 1996.

[45] Z. Xu, X. Yang, J. Chai, Y. Qin, and Y. Li, "Permeability characteristics of tailings considering chemical and physical clogging in lixi tailings dam, China," Journal of Chemistry, vol. 2016, Article ID 8147845, 8 pages, 2016.

[46] V. Banks and M. Kirkham, Hydraulic Characterisation of the Tailings Associated with the Abandoned Mine at Frongoch, Mid-Wales, N.E.R. Council, Nottingham, UK, 2011.

[47] B. D. Thompson, W. F. Bawden, and M. W. Grabinsky, "In situ measurements of cemented paste backfill at the Cayeli Mine," Canadian Geotechnical Journal, vol. 49, no. 7, pp. 755-772, 2012.

[48] E. Yilmaz, "Stope depth effect on field behaviour and performance of cemented paste backfills," International Journal of Mining, Reclamation and Environment, vol. 32, no. 4, pp. 273-296, 2018.

[49] H. Jiang, M. Fall, and L. Cui, "Freezing behaviour of cemented paste backfill material in column experiments," Construction and Building Materials, vol. 147, pp. 837-846, 2017.

[50] L. Cui, "M. Fall, "Multiphysics modeling and simulation of strength development and distribution in cemented tailings backfill structures," International Journal of Concrete Structures and Materials, vol. 12, no. 1, p. 25, 2018.

[51] L. Cui and M. Fall, "Modeling of pressure on retaining structures for underground fill mass," Tunnelling and Underground Space Technology, vol. 69, pp. 94-107, 2017.

[52] E. Yilmaz, "One-dimensional consolidation parameters of cemented paste backfills," Mineral Resources Management, vol. 28, no. 4, pp. 29-45, 2012. 